\title{
Para uma nova visão da Europa: aprender com o Sul
}

BOAUENTURA DE SOUSA SANTOS*

\section{Resumo}

O preconceito colonial constitui a chave para compreendermos a dificuldade que a Europa tem em aprender com o mundo, isto é, em reconhecer histórias, práticas, saberes e soluções para além da história e das teorias, alegadamente universais, produzidas no ocidente. Num momento em que várias crises assombram a Europa, parece existir uma janela de oportunidade para que, numa lógica de aprendizagens globais e de reconhecimentos recíprocos, a Europa possa abrir-se a aprender com o Sul, superando o pensamento abissal da modernidade. Este artigo procura compreender as condições para aprendizagens globais que permitam a reinvenção da Europa. Num primeiro momento, é analisado o lugar da Europa no mundo, considerando o auge do seu poder colonial e o mundo pós-colonial em que hoje vivemos. Em segundo lugar, são apresentadas as condições que podem permitir uma nova visão de uma Europa, a partir do hoje, que está fora dela. Por fim, são apresentados exemplos de aprendizagens mútuas em quatro áreas temáticas: direitos humanos, economia, democracia e constitucionalismo. ${ }^{1}$

Palavras-Chave: Europa. Epistemologias do Sul. Modernidade. Pensamento abissal. Aprendizagens globais.

\footnotetext{
${ }^{*}$ Centro de Estudos Sociais (CES) da Universidade de Coimbra (Portugal).

${ }^{1}$ Artigo elaborado no âmbito do projeto de pesquisa "ALICE - Espelhos Estranhos, Lições Imprevistas: Definindo para a Europa um novo modo de partilhar as experiências do Mundo", financiado pelo 7.. Programa-Quadro da União Europeia (FP/2007-2013)/ERC Grant Agreement no. 269807.
} 
Sociologias, Porto Alegre, ano 18,no 43, set/dez 2016, p. 24-56

\section{A new vision of Europe: learning from the South}

\section{Abstract}

Colonial prejudice is the key to understanding the difficulty that Europe has in learning from the world, that is, to recognise histories, practices, knowledges and solutions beyond the, allegedly universal, history and theories produced in the West. At a time when multiple crises loom over Europe, there appears to be a window of opportunity to, under global learnings and reciprocal recognitions, Europe open up to learn from the South, surpassing the abyssal thinking of modernity. This paper seeks to understand the conditions for global learnings enabling the reinvention of Europe. The argument is threefold: first, Europe's place in the world is analysed, considering the height of its colonial power and the postcolonial world we live in today; second, the conditions that can allow a new vision of a Europe, from the present that is outside it; finally, examples of mutual learnings in four thematic areas are presented: human rights, economy, democracy and constitutionalism.

Keywords: Europe. Epistemologies of the South. Modernity. Abyssal Thinking. Global Leanings

\section{Introdução}

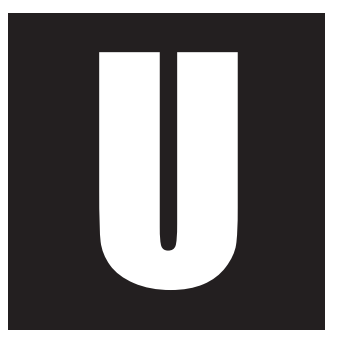

m sentimento de exaustão histórica e política assombra a Europa. Após cinco séculos a impor soluções ao mundo, num processo de expansão colonial iniciado pelas navegações ibéricas, a Europa parece incapaz de resolver os próprios problemas. O continente encontra-se envolto pela generalizada consciência de que não existem alternativas, de que é definitiva a perda do contrato social do Pós-Guerra que ligava ganhos de produtividade a ganhos salariais; e de que o aumento das desigualdades sociais, longe de criar crescimento económico, está a mergulhar a Europa numa profunda estagnação. A coesão social europeia degenera-se ante 
os nossos olhos, trazendo o espectro de uma guerra civil europeia, um fatum (destino avassalador) que Gottfried Leibniz (1646-1826) imaginava superado pela racionalidade moderna.

Esta situação é tanto mais intrigante, se considerarmos que alguns dos problemas aparentemente irresolúveis têm semelhanças com os que países não-europeus enfrentaram, com relativo sucesso, nos últimos anos. Ainda curioso é o facto de esses países terem partido muitas vezes de ideias e experiências europeias, sendo verdade que essas ideias e experiências foram profundamente reinterpretadas, cruzadas com elementos de origem não-europeia, num bricolage institucional e intelectual mais centrado em resultados concretos do que em dogmas e modelos ortodoxos.

O sentimento de exaustão é, pois, combinado com a ideia de miniaturização. A Europa parece encolher, ao mesmo tempo que o mundo não-europeu se expande. Novos atores, como os BRICS², emergem na cena global, enquanto a Europa se mostra cada vez menos relevante. Para abordar o presente, parto de duas premissas que estão longe de ser consensuais. Em primeiro lugar, a Europa, por mais extraordinários que tenham sido os seus feitos do passado, pouco tem a ensinar ao mundo, pelo menos por agora. Em segundo lugar, a Europa tem extrema dificuldade em aprender com as experiências não-europeias, em particular com aquelas que têm origem no Sul global. ${ }^{3}$

$\mathrm{O}$ preconceito colonial constitui a chave para compreendermos a dificuldade que a Europa tem em aprender com o mundo, isto é, em reconhecer histórias, práticas, saberes e soluções para além da história e das teorias, alegadamente universais, produzidas no ocidente. Em causa, está a produção de não existência através de um pensamento moderno

\footnotetext{
${ }^{2}$ Brasil, Rússia, Índia, China e África do Sul.

${ }^{3}$ Com o conceito de Sul global, refiro-me aqui às regiões periféricas e semiperiféricas e aos países do sistema mundo moderno, que foram denominados de Terceiro Mundo, após a Segunda Guerra Mundial.
} 
que tenho definido como abissal (Santos, 2007). No meu entender, o pensamento abissal moderno é-o, porque ainda largamente definido pela permanência das lógicas através das quais a experiência colonial moderna dividiu o mundo entre zonas metropolitanas e zonas coloniais. Ou seja, a força metafórica das linhas globais que dividiram o mundo ${ }^{4}$ sobrevive à cartografia literal que dividiu o velho do novo mundo em toda a modernidade colonial. Desse modo, subsistem as linhas abissais naquilo que é hoje o pensamento europeu e o pensamento ocidental, falamos de linhas que dividem a realidade social em dois universos distintos: o universo "deste lado da linha" e o universo "do outro lado da linha". A divisão é tal que, "o outro lado da linha" desaparece enquanto realidade, torna-se inexistente, e é mesmo produzido como inexistente. Inexistência, neste sentido, significa não existir sob qualquer forma de ser relevante ou compreensível (Santos 2007, p. 3-4). Colonialismo, evangelização, neocolonialismo, imperialismo, desenvolvimento, globalização, ajuda externa, direitos humanos, assistência humanitária são exemplos de algumas das diretivas das soluções eurocêntricas para os problemas do mundo. Imersa neste pensamento que arroga superioridade e cria fechamento, como pode a Europa aprender com experiências do mundo?

Parece existir uma janela de oportunidade, criada nas últimas duas décadas, a que a crise financeira, económica, política e ecológica tem dado nova visibilidade. Mas, e se a Europa, em vez de ser a solução para os problemas do mundo fosse ela mesma um problema? Afinal, será a Europa tão singular que tenha apenas que contar consigo própria? Ou será, ao invés, que a Europa é parte de um mundo com o qual pode e deve aprender?

\footnotetext{
${ }^{4}$ A primeira linha global moderna foi, provavelmente, o Tratado de Tordesilhas entre Portugal e Espanha (1494), mas as verdadeiras linhas abissais emergem em meados do século XVI com as amity lines (linhas de amizade).
} 
Sendo verdade que durante séculos a Europa assumiu o destino manifesto de evangelizar e civilizar os outros povos, dando lições ao mundo, ora escudada na grandeza do seu deus, ora anunciando a ciência moderna como a forma válida e universal de conhecimento, tal não implica que revertamos de forma simplista os termos da questão, afirmando que a Europa deve receber lições do Sul global. Não se trata, pois, de demonizar o pensamento europeu ou a ciência moderna europeia, mas de reconhecer as suas incompletudes. Do mesmo modo, o objetivo não é romantizar as inovações do Sul, mas abordá-las por meio de uma sociologia das ausências e das emergências, isto é, reconhecer experiências e conhecimentos invisibilizados e desvalorizados pelo pensamento colonial para pensar o futuro a partir de um presente dilatado, observando os sinais do presente como tendências ou embriões que podem ser decisivos no futuro (Santos, 2006).

É tempo de um entendimento pós-colonial e pós-imperial entre a Europa e o mundo. Nesse sentido, este texto procura responder a duas questões: Quais as condições que possibilitam as aprendizagens mútuas? Quais as áreas essenciais nestas aprendizagens globais? O argumento é apresentado em três partes. Num primeiro momento, analiso as duas premissas mencionadas, contextualizando historicamente o declínio da Europa. No segundo ponto, apresento as condições para ocorrerem aprendizagens mútuas, nomeadamente a disponibilidade para aprender com o Sul e a aceitação de que o mundo do futuro é pós-europeu. Finalmente, apresento alguns exemplos de aprendizagens mútuas em quatro áreas temáticas: direitos humanos e interculturalidade, desenvolvimento sustentável e outras economias, democracia e constitucionalismo intercultural. 


\section{A Europa no mundo}

Até o século XV, a Europa é a periferia de um sistema-mundo cujo centro está localizado na Ásia Central e na Índia. Só a partir de meados do milénio, com as navegações ibéricas, é que esse sistema-mundo é substituído por outro, capitalista e planetário, cujo centro é a Europa. As sucessivas cruzadas selaram a conceção do Oriente que dominou durante todo o milénio - o Oriente como civilização temível e temida e como recurso a ser explorado pela guerra e pelo comércio - e teve a sua consagração científica no século XIX com o chamado Orientalismo. ${ }^{5} \mathrm{O}$ outro lado do Orientalismo foi a ideia da superioridade intrínseca do Ocidente.

Se o Oriente é para o Ocidente o lugar da alteridade, a América e a África, enquanto "descobertas" ocidentais, são o lugar por excelência do selvagem. É a propósito da América e dos povos indígenas submetidos ao jugo europeu que nasce o debate fundador sobre a conceção do selvagem. Este debate que, contrariamente às aparências, está hoje tão em aberto como há quatrocentos anos, inicia-se com as viagens marítimas de Cristóvão Colombo e Pedro Álvares Cabral e atinge o seu primeiro clímax na "Disputa de Valladolid", convocada em 1550 por Carlos V. Neste debate, confrontaram-se dois discursos paradigmáticos sobre os povos indí-

\footnotetext{
${ }^{5}$ O Orientalismo é a conceção do Oriente que domina nas ciências e as humanidades europeias a partir do final do século XVIII. Segundo Edward Said (1979), essa conceção assenta nos seguintes dogmas: uma distinção total entre "nós", os ocidentais, e "eles", os orientais; o Ocidente é racional, desenvolvido, humano, superior, enquanto o Oriente é aberrante, subdesenvolvido e inferior; o Ocidente é dinâmico, diverso, capaz de autotransformação e de autodefinição, enquanto o Oriente é estático, eterno, uniforme, incapaz de se autorrepresentar; o Oriente é temível (seja ele o perigo amarelo, as hordas mongóis ou os fundamentalistas islâmicos) e tem de ser controlado pelo Ocidente (por meio da guerra, ocupação, pacificação, investigação científica, ajuda ao desenvolvimento, etc.). Max Weber (1990) foi um dos grandes teorizadores do predomínio inevitável do Ocidente. O facto de Joseph Needham (1954) e outros terem demonstrado que, até ao século $\mathrm{XV}$, a civilização chinesa não era em nada inferior à civilização ocidental, não abalou até hoje o senso comum ocidental sobre a superioridade, por assim dizer, genética do Ocidente
} 
genas e a sua dominação, protagonizados por Juan Ginés de Sepúlveda (1979), para quem os índios são inferiores e, por isso, os escravos naturais, e Bartolomé de Las Casas (1992), que os considerava seres racionais e livres, dotados de cultura e instituições próprias, com os quais a única relação legítima era a do diálogo construtivo. O paradigma de Sepúlveda prevaleceu, porque só esse era compatível com as necessidades do novo sistema mundial capitalista centrado na Europa, que definiu o sistema-mundo moderno em que vivemos.

O período alto da Europa como poder global e imperial terminou em 1945. Devastada, beneficiou da ajuda dos EUA, país reposicionado pela guerra em esmagadora potencia mundial. Quando os EUA entraram em declínio na década de 1970, a Europa, ao invés de implementar uma trajetória nova e autónoma, uniu o seu destino ao dos EUA, desenvolvendo uma parceria que, com o passar dos anos, se tornou cada vez mais desigual. Quando os países periféricos do Sul global, muitos dos quais antigas colónias europeias, se tornaram independentes e tentaram traçar a sua história num mundo pós-europeu, a jornada foi acidentada. Por um lado, Europa e EUA questionaram e desafiaram qualquer tentativa de desvinculação do sistema capitalista, por outro, a União Soviética recusou qualquer alternativa que não a sua.

O movimento dos não-alinhados (iniciado com a Conferência de Bandung, em 1955) foi a primeira manifestação de intenção histórica de desenhar um caminho que fosse além da visão bipolar e contraditória que a Europa oferecia ao mundo - ora liberal e capitalista, ora marxista e socialista, dois lados altamente excludentes e exigindo lealdade incondicional. Esta dicotomização nos assuntos mundiais, dramaticamente ilustrada pela Guerra Fria (por vezes, muito quente, como por exemplo na guerra da Coreia ou nas guerras na África Austral), colocou dilemas políticos irresolúveis às novas elites políticas do Sul global, ao nível nacional, regional 
e das Nações Unidas. Tal sucedeu mesmo com as elites mais distanciadas da cultura ocidental capitalista e comunista, aquelas que percebiam ambos os sistemas como armadilhas gémeas assentes na supremacia do "homem branco".

Nas décadas seguintes, surgiram tentativas de construir uma história com algum grau de autonomia, até que se deu a emergência dos BRICS, no final do século XX. Esta emergência dramatizou a diversidade da experiência do mundo que, em todo o caso, sempre subsistiu, nas mais diferentes formas de resistência e apropriação criativas, nas lutas desenvolvidas pelos grupos que lutaram e lutam contra as formas de opressão causadas pelo colonialismo, pelo capitalismo e pelo patriarcado.

Ante o desperdício desta diversidade de experiência no mundo, refletir sobre as condições que possibilitam a aprendizagem mútua implica a possibilidade de construção de uma nova visão da Europa, reconhecendo que a antiga, no mínimo, perdeu a incontestada validade e funcionalidade. Curioso paradoxo: neste momento, muitos europeus aspiram a uma nova visão da Europa, mesmo sem saberem em que termos essa nova visão diferirá da antiga, que é, na melhor das hipóteses, uma vaga noção. A antiga visão da Europa só pôde parecer sólida e precisa pelo modo como, em cada momento, foi sendo simultaneamente modelada e afirmada incontestável, pelos poderes que nela se foram imbricando.

Entre incertezas e paradoxos que fogem ao âmbito deste artigo, cabe perguntar o que qualificamos como Europa. Quantas Europas existem? É constituída por 51 países ou pelos 28 países da União Europeia? O que significa ser europeu? Devemos ter em mente que não existe qualquer definição oficial de "europeu", pelo menos em termos de políticas culturais. A desintegração da União Soviética, a reunificação da Alemanha e o movimento em grande escala de migrantes, trabalhadores e refugiados acrescentaram complexidade à ideia de Europa e à identidade europeia, 
na medida em que novas identidades e fronteiras se justapuseram tendo-se formado divisórias múltiplas dos estatutos de "íntimo" ou "estranho". É de supor que os serviços de migração e fronteiras possam desenvolver ideias particulares sobre o que seja a Europa e a sua identidade. Por esta razão, alguns autores defendem que o discurso da "identidade europeia" é prematuro (e.g. Shore, 1993). Tal como não existe "uma Europa", mas antes uma pluralidade de definições históricas específicas e concorrentes entre si (Seton-Watson, 1985; Wallace, 1990), existem "identidades europeias" contrastantes e rivais, dependentes do desenho das fronteiras e da perceção da natureza da "Europeidade" (Kundera, 1984; Dahrendorf et al,. 1989). Ao mencionar estas complexidades e incertezas, saliento o quanto uma nova visão da Europa terá de estar intimamente ligada à ideia das múltiplas fronteiras da Europa, frequentemente contraditórias.

\section{Aprender com o Sul}

Dado o passado histórico imperial europeu, a primeira condição para a aprendizagem mútua é a disponibilidade para aprender a partir do Sul global, com as experiências de imensas regiões do mundo que estiveram sujeitas ao jugo europeu. O Sul invoca uma geografia e uma cartografia, mas no sentido que aqui lhe atribuo, é uma metáfora do sofrimento humano injusto provocado pelo capitalismo, pelo colonialismo e pelo patriarcado (Santos, 2014, p.215). Claro que este sofrimento não resulta exclusivamente da ação da Europa. Historicamente, os europeus também lutaram contra o colonialismo, o capitalismo e o patriarcado. A metáfora remete para medidas, escalas e pesos, para dominantes e subalternos, para movimentos maioritários e minoritários e para tendências. $E$ tudo isto nos diz que durante séculos a Europa foi um centro fortíssimo que governou o mundo criando periferias subalternas e margens. 
A primeira condição de aprendizagem com o Sul passa pelo esclarecimento de que tipo de Sul ou Suis devem ser incluídos neste entendimento. Este esclarecimento pressupõe uma vontade de considerar uma nova cartografia da Europa. Nas primeiras décadas do século XIX, o estadista austríaco Metternich escrevia que "Asien beginnt an der Landstras$\mathrm{se}^{\prime \prime}$, isto é, a Ásia começa na periferia de Viena ocupada pelos imigrantes provenientes dos Balcãs. No século XIX, a zona em torno da Landstrasse era ocupada por imigrantes dos Balcãs. Então, como agora, a distinção entre os Balcãs e a Europa era marcada, como se os primeiros não pertencessem à Europa.

O significado de Sul é particularmente complexo no caso da Europa. O Sul que confronta a Europa como outro existe tanto dentro como fora da Europa. O Sul fora da Europa é constituído pelos países fornecedores de matéria-prima com mercados de consumo a explorar; países cujas catástrofes naturais tornam lícita a ajuda humanitária europeia; países incapazes de sustentar a sua população dando origem ao problema da imigração que "aflige" a Europa; países que criam terroristas contra os quais é necessário lutar com a máximo inclemência. O Sul dentro da Europa é constituído, por exemplo, pelos ciganos/roma, pelos imigrantes, e pelos filhos dos imigrantes - alguns dos quais nascidos nesta mesma Europa há várias gerações, portadores de passaportes europeus, sem no entanto serem tidos como "europeus como os outros".

Existe, contudo, um outro Sul dentro da Europa. É um Sul geográfico porém igualmente cabível no Sul metafórico. Refiro-me aos países do Sul da Europa, em particular Grécia, Espanha e Portugal. ${ }^{6}$ A depreciação dos países do Sul é histórica e encontra-se bem documentada. Por exemplo, entre o século XV e o século XVIII, encontramos inúmeras narrativas de via-

${ }^{6}$ Para uma análise da situação subalterna de Portugal na Europa, mesmo quando era um império colonial, ver Santos, 2011, p.: 53-64. 
jantes e comerciantes do norte da Europa que enfatizavam as condições de vida precárias na Europa do Sul.7 Estas narrativas atribuíam aos portugueses e aos espanhóis as mesmas características que os colonizadores portugueses e espanhóis imputavam aos povos selvagens e primitivos das suas colónias: condições de vida precárias, preguiça e lascívia, violência, afabilidade, negligência higiénica, ignorância, superstição, irracionalidade, etc.

Nas circunstâncias atuais, é difícil imaginar a Europa a aprender com os países do seu Sul. Os mais cínicos dirão mesmo que com eles só se aprende o que não fazer. Esta afirmação tem raízes históricas profundas. Para as entender é necessário recuar cinco séculos e prestar atenção à oscilação histórica entre centros e periferias dentro da Europa. Um centro mediterrânico que não durou mais de século e meio (século XVI e metade do século XVII) foi suplantado por outro orientado para o Atlântico Norte, para o Mar do Norte e o Mar Báltico, abarcando cidades do norte de Itália, de França, dos Países Baixos e, no século XIX, da Alemanha. Este centro esteve sempre rodeado de periferias: a norte, os países nórdicos; a Sul, a Península Ibérica; a Sudoeste, os Balcãs; a Este, os territórios feudais do Império Otomano e da Rússia (semieuropeizada desde o século XVIII sob o domínio de Pedro, o Grande). Ao longo de cinco séculos, apenas as periferias do norte tiveram acesso ao centro que hoje continua a ser o núcleo da União Europeia. A verdade é que, tal como refere Hobsbawn (1997), sempre houve duas Europas e muitas vezes duas Europas dentro de cada país (Catalunha e Castela em Espanha, Itália do Sul e a Itália do Norte, etc.).

Esta dualidade que define um Sul na Europa está mais arraigada na cultura europeia do que se poderia pensar, e explica algumas das dificuldades na abordagem da crise financeira que se faz sentir na Europa, desde 2008. O que aparenta ser apenas um problema económico ou financeiro é também um problema cultural e sociopsicológico. Entendo

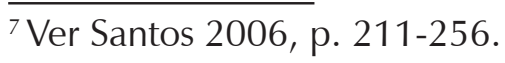


que esta dimensão mais profunda pode estar mais presente nas soluções económicas e financeiras do que se poderia pensar.

A segunda condição para uma aprendizagem com o Sul é a aceitação da evidência de que o mundo do futuro será um mundo pós-europeu. $\mathrm{O}$ futuro não será ditado ao mundo pela Europa como foi no passado. A empresa colonial estipulava que as populações e nações sujeitas à governação europeia, independentemente da diversidade da herança histórica, estavam condenadas a um futuro ditado pela Europa. Deste modo, o futuro da Europa ficou refém dos limites que impunha aos outros. Quantas ideias e projetos foram descartados, desacreditados, abandonados, demonizados dentro da Europa, por simplesmente não servirem o projeto colonial? A visão do futuro não é alcançável sem que a Europa faça contas com o passado, inclusivamente celebrando a libertação alcançada pelos países cuja trajetória está presa ao passado colonial europeu.

No entanto, uma vez fechado o ciclo do colonialismo histórico, o neocolonialismo provou ser um fardo resiliente para vários países, reproduzido por uma vasta gama de políticas, algumas mais benevolentes que outras, que vão da intervenção militar aos programas de desenvolvimento, dos direitos especiais sobre recursos naturais à assistência humanitária. A ilusão de uma interrupção pós-colonial não permite aos governos da Europa escrutinar criteriosamente as operações globais das empresas europeias, estejam elas a promover alimentação para bebés em regiões de fome, a usurpar terras, a especular com bens alimentares, a reivindicar patentes sobre medicamentos, a restringir o acesso dos camponeses a sementes ou a provocar catástrofes ambientais.

Longe de constituir apenas um imenso espaço de vitimização, o mundo colonial representa um lugar multifacetado de resistência e arte de sobrevivência. Aqui, reside a imensidão da experiência do mundo, que poderia ser mais vasta não fosse o epistemicídio, isto é, a destruição 
maciça de experiências e conhecimentos subordinados, considerados inadequados para servir o projeto colonial (Santos, 2014, p. 236). Este passado não pode ser desfeito, mas o modo como condiciona o nosso presente deveria ser objeto de reflexão profunda e transformação política. Deste modo, reivindicar a necessidade de uma leitura pós-colonial não é sustentar uma obsessão interpretativa fundada na experiência colonial, é sim reconhecer a fortíssima herança histórica do colonialismo nas estruturas de poder e saber nas sociedades pós-coloniais, ${ }^{8}$ bem como a relevância das referências inspiradoras dos movimentos de liberação anticoloniais para pensar as lutas do presente (Young, 2001).

\section{Aprendizagens globais}

A Europa tem de voltar à escola, à escola do mundo e da sua diversidade infinita, dispondo-se a desaprender muitas das conceções sobre si própria tidas como autoevidentes, que foram verdadeiras e úteis no passado, mas deixaram de o ser, dispondo-se, ainda, a aprender sobre novas ideias, algumas inteiramente não familiares, outras tão estranhas como se fossem o reflexo num espelho surpreendente, ou seja, ideias europeias, há muito descartadas e esquecidas por terem sido excluídas da vastíssima família das ideias europeias. Enquanto regressa à escola, a Europa deve aceitar a possibilidade de algumas das suas mais antigas e vibrantes tradições poderem hoje ser encontradas fora de Europa, após serem apropriadas e criativamente transformadas pelos povos subjugados ao colonialismo europeu e ao pós-colonialismo. Como exemplos fortes, apresento algumas lições de desaprendizagem e aprendizagem em quatro áreas: direitos humanos, economia, democracia e constitucionalismo.

${ }^{8}$ Continuidade que tem sido denominada por "colonialidade do poder" (Quijano, 2000; Dussel, 2001; Mignolo, 2000). 


\subsection{Direitos Humanos e Interculturalidade}

Desde a Segunda Guerra mundial, a Europa tem enfrentando um desafio intercultural relativamente à coesão jurídica e política, resultante não apenas dos processos migratórios, mas também do reconhecimento da diversidade subnacional. Uma vez mais, a distinção interior-exterior é crescentemente transformada em divisão interior-interior. À medida que a diferença cultural se torna uma dimensão da cidadania cultural, as questões dos direitos humanos e dos direitos de cidadania estão mais coimplicadas do que nunca, ainda que as forças conservadoras tentem separá-las. A demanda por uma noção de cidadania europeia mais ampla, partindo do tradicional âmbito nacional de cidadania no sentido de uma escala europeia amplificada, é fundamental à ideia de uma conceção cosmopolita de humanidade e de direitos humanos. Em meu entender, a defesa da interculturalidade e dos direitos humanos é cada vez mais a mesma luta. Contudo, num mundo pós Set/11, o apelo à interculturalidade tornou-se simultaneamente mais difícil e necessário. Por um lado, existe o perigo de que uma conceção limitada de segurança reprima a interculturalidade face a um receio de perda de controlo; por outro, torna-se evidente que a vítima de tal conceção não é apenas a interculturalidade, mas o cerne dos direitos humanos, tal como foram convencionalmente entendidos na Europa.

Não existe dúvida sobre a hegemonia dos direitos humanos enquanto discurso de dignidade humana (Santos, 2013, p 1-10). No entanto, tal hegemonia enfrenta uma realidade perturbadora. $\mathrm{O}$ facto é que a grande maioria da população mundial não é sujeito de direitos humanos, mas objeto de discursos de direitos humanos. A questão é se os direitos humanos constituem uma ajuda eficaz nas lutas dos excluídos, dos explorados e dos discriminados, ou se, pelo contrário, dificultam mais as suas lutas. Por outras palavras, a hegemonia reivindicada pelos direitos humanos resulta de uma vitória histórica ou de uma derrota histórica? 
Temos de começar por reconhecer que os direitos humanos têm uma dupla genealogia na modernidade europeia, uma genealogia imperial e uma genealogia revolucionária. Esta genealogia imperial tem mostrado como os direitos humanos representam, muitas vezes, os "direitos do poder" e não "o poder dos direitos" (Falk, 2009). Os direitos humanos hegemónicos ou convencionais são-no por resultarem da sua origem monocultural ocidental, por terem estado ao serviço dos duplos critérios e das justificações imperialistas na arena geopolítica, e por se constituírem hoje como denominadores mínimos de direito, conquanto congruentes com a ordem global individualista, neoliberal e nortecêntrica. Por outro lado, os direitos humanos foram, por vezes, um instrumento poderoso na luta pela democracia e pela decência e contra a tirania e a opressão conduzidas por agentes estatais e não-estatais, articulados com outras gramáticas de dignidade contra os poderes estabelecidos.

A Europa teve sempre dificuldade em reconhecer a existência de outras gramáticas de dignidade humana para além da dos direitos humanos. No entanto, basta lembrar que os movimentos de libertação nacional do século XX não invocaram a gramática dos direitos humanos para justificar as suas causas e lutas, lutando em nome da libertação nacional e da autodeterminação (Moyn, 2010).

Hoje em dia, duas outras gramáticas de dignidade humana convocam um envolvimento europeu ativo. A primeira, não sendo estranha às raízes europeias - mas tida como não-europeia - encontra-se nas conceções islâmicas de dignidade humana e na ênfase nos deveres, e não nos direitos, bem como na valorização da comunidade (umma) como raiz suprema da dignidade e do mérito humano. Aliás, existe um longo debate sobre as relações entre o islamismo e os direitos humanos e a possibilidade de uma conceção islâmica dos mesmos ${ }^{9} \mathrm{~A}$ islamofobia feroz que atualmente flagela

$\overline{{ }^{9} \text { Ver, por exemplo, }}$ An-na'im (1990, 1992). 
a Europa impede um diálogo produtivo com um quinto da população mundial e com uma percentagem crescente dos seus cidadãos.

Sobre este assunto, ainda existe uma outra plataforma, para um novo diálogo com o mundo pela desaprendizagem/aprendizagem, digna de salientar. Refiro-me ao secularismo. O secularismo é um paradigma arraigado no modo de vida europeu. A trágica experiência dos séculos XVI e XVII deixou a Europa sem qualquer outra alternativa positiva que não fosse a separação do Estado e da Igreja, segundo a ideia de que a liberdade religiosa só se consegue numa sociedade cuja esfera pública está liberta da religião. Não discutirei aqui as complexidades da solução europeia para a questão religiosa. Gostaria apenas de enfatizar que, por motivos complexos, parece que estamos a entrar numa era pós-secular, tal com Charles Taylor (2007) Ihe chama. Do mesmo modo, também Habermas (2009) falou de uma pós-secularidade como uma das características definidoras do nosso tempo. A minha opinião sobre este assunto é que estamos a dirigir-nos para tempos difíceis, nesse sentido a participação da Europa no diálogo mundial deveria articular-se com a importância da distinção entre secularismo e secularidade. A secularidade é uma postura filosófica e política que defende a separação do estado e da religião, mas que admite a presença de posições não-seculares na esfera pública, enquanto o secularismo é a incorporação da própria esfera pública tornando-se a única fonte de autoridade para a razão pública, não deixando, portanto, espaço para as atitudes não-seculares no domínio público.

A outra gramática que apela ao desaprender/aprender por parte da Europa é a dos direitos da natureza. Refiro-me à luminosa inovação plasmada na Constituição do Equador, de 2008. A relação do Estado com a Natureza é aí determinada pelo sistema de vida definido na Constituição como Sumak Kawsay (oposto ao sistema capitalista e desenvolvimentista) 
e condicionado pelos direitos da Pachamama ou Natureza. ${ }^{10}$ Em termos culturais, os direitos da natureza configuram uma entidade híbrida que se apropria da ideia europeia de direitos humanos, combinando-a com as cosmovisões indígenas da natureza (Orbe, 2010). Desde Descartes que a cosmovisão europeia dominante reduziu a natureza a res extensa (uma identidade corpórea sem alma), e como tal, a desguarneceu da dignidade concedida às criaturas humanas vivas. Dada a profunda crise ecológica em que vivemos, proponho que se aprenda com estas conceções de natureza e direitos através do que denomino por tradução intercultural. ${ }^{11}$ Se o conseguíssemos, seríamos testemunhas de um fascinante bumerangue cultural: os direitos humanos teriam deixado a Europa impondo humanos contra natureza, teriam atravessado o mundo e regressado, voltando a unir e humanidade e natureza.

À luz desta diversidade de visões sobre a dignidade dentro e fora da Europa, proponho, contra o universalismo tradicional, diálogos interculturais sobre conceitos isomorfos, como os direitos humanos ocidentais, o conceito de dharma Hindu, a conceção umma islâmica, a pachamama ou o buen vivir dos povos indígenas da América Latina, e o ubuntu da sabedoria africana. Como resultado, uma hipotética visão de

\footnotetext{
${ }^{10}$ Conforme se refere no artigo 71: A natureza ou Pachamama, onde se reproduz e se realiza a vida, tem direito a que se respeite integralmente a sua existência e a manutenção e a regeneração de seus ciclos vitais, estrutura, funções e processos evolutivos. Toda pessoa, comunidade, povoado, ou nacionalidade poderá exigir da autoridade pública o cumprimento dos direitos da natureza. Para aplicar e interpretar estes direitos, observar-se-ão os princípios estabelecidos na Constituição no que for pertinente. O Estado incentivará as pessoas naturais e jurídicas e os entes coletivos para que protejam a natureza e promovam o respeito a todos os elementos que formam um ecossistema.

${ }^{11}$ A tradução intercultural consiste na busca de preocupações isomórficas e de premissas inerentes entre culturas, identificando diferenças e similitudes, e desenvolvendo, sempre que apropriado, novas formas híbridas de entendimento cultural e intercomunicação que podem contribuir para favorecer interações e fortalecer alianças entre os movimentos sociais que, em diferentes contextos culturais, lutam contra o capitalismo, colonialismo e patriarcado e pela justiça social, dignidade humana, ou decência humana (Santos 2014,p. 212-235).
} 
dignidade humana poderia ser amplamente aceite na Europa: temos o direito a ser iguais quando a diferença nos inferioriza, temos o direito a ser diferentes quando a igualdade nos descaracteriza.

\subsection{Alternativas ao desenvolvimento e outras economias}

Neste início do século XXI, a tarefa de pensar e lutar por opções económicas e sociais é particularmente urgente. Em primeiro lugar, vivemos numa época em que a ideia de inexistência de alternativas ao capitalismo alcançou um grau de aceitação sem precedentes na história do capitalismo mundial. Nas últimas duas décadas do século XX, as elites económicas, políticas e intelectuais conservadoras impulsionaram com tal agressividade e êxito o pensamento neoliberal, que a ideia de que não há alternativa ao capitalismo neoliberal ganhou credibilidade mesmo entre os círculos políticos e intelectuais progressistas. No entanto, a história do capitalismo, desde o seu aparecimento no que Wallerstein (1979) chamou de "longo século XVI", é também a história das lutas de resistência, que assumem formas variadas e apontam diferentes direções, indo desde a vasta tradição de pensamento crítico que reivindica um desenvolvimento alternativo, à rejeição da ideia de desenvolvimento económico defendida por alguns grupos nos países do Sul.

O primeiro exercício de desaprendizagem/aprendizagem no âmbito das alternativas ao desenvolvimento e de outras economias implica revisitar o mundo enquanto campo de trocas desiguais. A prosperidade da Europa foi construída com a transferência de riqueza do Sul global, primeiro das colónias e posteriormente com as lógicas neocoloniais. À luz das recentes controvérsias comerciais que opõem a Europa ao Sul global, uma dimensão relevante de desaprendizagem/aprendizagem reside na ideia de que aquilo que é bom para as empresas europeias não é necessariamente bom para a Europa. Dado o investimento massivo em lobbying por parte de corporações europeias e não europeias em Estrasburgo e em Bruxelas, 
esta será uma aprendizagem desafiadora. Neste contexto, as declarações de líderes europeus sobre a necessidade de relações mais horizontais e inclusivas, fundadas na cooperação e no respeito mútuo, serão tidas pelos parceiros não-europeus como meras operações cosméticas de fachada.

O segundo exercício de desaprendizagem/aprendizagem remete para as alternativas ao desenvolvimento e para o papel das relações económicas não-capitalistas nas sociedades capitalistas. A crise financeira e económica tornada visível em 2008 sublinhou os impasses atuais respeitantes às decisões sobre as alterações climáticas e o desenvolvimento sustentável, enfatizando a triste marginalização da Europa neste campo, em lugar de uma posição de liderança nas políticas energéticas amigas do ambiente. Por outro lado, novas iniciativas estão a acontecer noutras partes do mundo. A reivindicação da terra pelos camponeses, que parecia historicamente condenada, conhece na América Latina, em África e na Índia uma força enorme. Organizações económicas não-capitalistas - frequentemente apelidadas por economia solidária ou outras economias - proliferam em países tão diversos quanto o Brasil, a África do Sul, Moçambique e a Índia. Mudanças políticas recentes em alguns países declararam uma moratória aos conceitos convencionais de desenvolvimento económico e enquadraram as suas políticas económicas recorrendo a conceções não-ocidentais, tais como o Sumak Kawsay ou Sumak Qamaña (bem viver, em Quechua e Aymara, respectivamente). Assim, mesmo que envolvidas em controvérsias internas e internacionais, várias iniciativas apontaram caminhos pós-capitalistas e pós-desenvolvimentalistas em termos não-utópicos, ou seja, traduziram visões em agendas políticas concretas. $^{12}$ Do lado europeu, as atuais crises financeiras, económicas,

\footnotetext{
${ }^{12} \mathrm{O}$ Equador forneceu um notável exemplo, avançando com a proposta mais inovadora num mundo pós-Quioto: manter inexploradas no subsolo as imensas reservas de petróleo do parque Nacional Yasuni-ITT - considerado pela UNESCO como a região mais rica do mundo em biodiversidade - sob a condição de que as economias industrializadas compensassem o país com metade do valor da receita que obteria com exploração de petróleo. Era uma ideia
} 
energéticas e ambientais são sinais evidentes da necessidade de ter em conta os indícios, no mundo, da emergência de um novo senso comum social e económico. Apesar do progresso significativo na política energética, a Europa não conseguiu afirmar uma liderança no debate global sobre desenvolvimento sustentável e desenvolvimento alternativo. Os interesses económicos organizados e as suas políticas de influência bloqueiam ativamente estes movimentos e as transformações paradigmáticas a que se dirigem. Todavia, a tendência parece irreversível e carece apenas de um alargamento dos desígnios, de uma perspetiva internacional e de uma oportunidade política para experimentação social, de modo a que possa tornar-se um fator central da agenda política a nível europeu.

\subsection{Democratizar a democracia}

A coexistência pacífica ou conflitual de diferentes modelos e práticas democráticas foi dando lugar à consagração da democracia liberal como modelo único e universal, na segunda metade do século passado. A imposição deste modelo fica bem patente pelo modo como o Banco Mundial e o Fundo Monetário Internacional o transformam em condicionalidade política para a concessão de empréstimos e ajuda financeira. Esta universalidade é problemática, na medida em que a democracia tem um valor intrínseco e não deve constituir uma mera utilidade instrumental, portanto, esse valor não pode assumir-se como universal sem mais. Está inscrito numa constelação cultural específica, a da modernidade ocidental, e essa constelação, por coexistir com outras num mundo que ago-

totalmente revolucionária, que veio recentemente a revelar-se o plano B de uma agenda que passou sempre pela exploração do petróleo e que envolve a expulsão de camponeses, a criminalização de protestos e a contaminação de águas. Para manter a redistribuição social, o governo aprofundou o modelo neoliberal de acesso aos recursos. Trata-se de um exemplo de desperdício de uma oportunidade para transformar o modelo neocolonial que atribuiu ao Sul o papel de fornecedor de recursos naturais. 
ra se reconhece como multicultural, não pode, simplesmente, reivindicar a universalidade dos seus valores.

Por outro lado, o avanço do modelo de democracia liberal tem mostrado como os avanços e triunfos da democracia representativa estão de mãos dadas com o reconhecimento crescente dos seus limites. Em particular, a expansão global da democracia liberal coincidiu com a crise da dupla patologia nos países centrais onde estava mais consolidada: a patologia da participação, sobretudo em vista do aumento dramático do abstencionismo; e a patologia da representação, com os cidadãos a sentirem-se cada vez menos representados por aqueles que elegeram (Santos; Avritzer, 2002).

Na União Europeia, vive-se o problema do espaço democrático, as suas condições de viabilidade, os seus dois défices, por um lado, o que resulta do que Jürgen Habermas (2012) denominou de "federalismo executivo pós-democrático"; por outro, as aporias que resultam da divisão, cada vez mais notória, entre países fortes e países fracos, dado que contraria a igualdade formal enquanto Estados-membros. Este último défice deu origem a um divórcio ideológico entre o Norte e o Sul, em termos de confiança política e de legitimidade democrática. Análises sistemáticas de inquéritos de opinião mostram que as democracias do Norte recuperaram e ultrapassaram os níveis de confiança e de satisfação com o sistema político; enquanto, nas democracias no Sul, os níveis de confiança política e satisfação se encontram em queda. À primeira vista, isto pode parecer surpreendente, já que, na Europa, tanto do Norte como do Sul, os governos prosseguem com uma série de políticas de austeridade. Aquilo que aproxima os cidadãos do Norte aos seus governos é o facto de essas políticas serem mais suaves do que as aplicadas aos cidadãos do Sul. Está em marcha um insidioso processo de legitimação, processo esse que consiste em colocar europeus contra europeus. Será possível construir uma demos europeia com tal fundamento? 
Em face da crise financeira ou do crescimento de um populismo extremo, o desinteresse, a desconfiança e a insatisfação com o regime democrático representativo estão a tornar-se tão profundos que, em vez de terem um impacto positivo na política democrática, ativando novas e intensas formas de envolvimento político, alimentam a resignação maciça e a apatia, a distância crescente entre os cidadãos e os políticos eleitos e a sensação de desconfiança face à democracia. Nos países em que decorre um ajuste estrutural, as pessoas estão de tal forma preocupadas com a sobrevivência e o sustento das suas famílias, que a liberdade de escolha, a autonomia individual e a responsabilidade, prometidas pelo neoliberalismo, estão a tornar-se pesadelos cruéis.

Felizmente, esta não é a história toda. Os jovens e os cidadãos em geral vão enchendo as ruas e praças das cidades europeias do Sul, em protesto contra o que consideraram a maior e mais escandalosa transferência de riqueza, das classes pobres e médias para os ricos e os super-ricos, alguma vez testemunhada em regime democrático. Não se tratou de protestos desesperados contra uma circunstância injusta, mas um protesto pacífico levado a cabo em nome de uma ideia nobre: a democracia real. Porquê real? Porque a atual deixou de o ser. Tornou-se um fantasma institucional, uma concha vazia, em cujo interior operam, livremente e sem prestação de contas, interesses poderosos manipulando a governação política e a opinião pública.

Está a tornar-se cada vez mais evidente para muitos cidadãos europeus que a integração foi um processo conduzido por elites económicas e políticas, com o propósito voluntário ou involuntário de os isolar das pressões e aspirações da cidadania. A crise do euro é a mais dramática evidência desta realidade, revelando como a democracia, tal qual a conhecemos, vem sendo derrotada pelo capitalismo, na versão mais antissocial: o capitalismo financeiro global desregulado. A presente crise revela 
uma assimetria inquietante: a democracia representativa talvez imponha limites ao capitalismo, mas também pode ser absorvida ou derrotada por ele. O contrário não é contudo verdade: o capitalismo pode colocar limites à democracia, que esta não consegue absorver ou contornar, correndo o risco de perder significado para os cidadãos. Dito de outro modo, a democracia não é capaz de substituir o capitalismo pelo socialismo, mas o capitalismo pode trocar a democracia pela ditadura como a história europeia provou amiúde no passado.

Neste contexto, é necessário um exercício de desaprendizagem/ apredizagem na escola do mundo. Os cidadãos da Europa sentem necessidade de formas mais densas de governação democrática. A Europa tem de desaprender a certeza da democracia representativa como modelo único e inquestionável. Por muito precioso que seja, trata-se de um modelo cada vez menos capaz de se defender de inimigos que o usam com o único propósito de minar e ulteriormente abolir a democracia. A democracia representativa tem que ser complementada e revigorada pela democracia participativa, isto é, por formas e áreas de deliberação democrática pelas quais os cidadãos, em vez de elegerem quem decide, tomam decisões dentro dos limites e em função da regulamentação acordada. Esta conjugação virtuosa entre a democracia representativa e participativa foi experimentada com grande sucesso na América Latina, em particular no Brasil (Santos, 2002a, 2002b). O sucesso tem sido tal que, ainda que timidamente, algumas cidades europeias vêm tentando reproduzir a experiência da América Latina, no que se refere, em particular, à implementação de sistemas de orçamento participativo.

Este processo de aprendizagem deve ser intensificado, tendo como premissa a ideia de que a luta por uma Europa mais unida e por um conjunto de nações internamente mais coesas só será possível com a expansão dos domínios em que a razão do lucro seja substituída por uma 
deliberação política que se oponha ao regresso da lógica de mercado. Essa mudança será mais consistente, quando cidadãos comuns tomarem decisões em matérias que afetam diretamente as suas vidas. Não me refiro a utopias longínquas. Falo de orçamento participativo, de conselhos populares de saúde e de educação, de conselhos de desenvolvimento económico e social a cuja pujança vamos assistindo pelo mundo.

Assim sendo, um segundo exercício de desaprendizagem/aprendizagem é recomendável. A Europa, a mãe da social-democracia, assistiu ao desmantelamento deste regime político a um ritmo dramático, após a queda do Muro de Berlim. ${ }^{13} \mathrm{Se}$, ainda assim, formos suficientemente corajosos para exercitar alguma dúvida do senso comum e olharmos a experiência do mundo, seremos surpreendidos ao constatar que alguns países de fora da Europa, incluindo a Argentina, o Brasil, o Equador, a Bolívia, assumem ter sido inspirados pela social-democracia europeia e dela se terem reapropriado criativamente, de modo a adaptá-la às condições locais e internacionais. Isto foi conseguido através de políticas democráticas ratificadas pelas populações em eleições sucessivas. Ao fazê-lo, conseguiram alcançar, em escala significativa, uma redistribuição social da riqueza, sem embarcar na nacionalização massiva ou na presunção de estar a construir o socialismo e sem fechar os seus países aos fluxos económicos transnacionais. O único ato de desobediência cometido por todos foi em relação ao Fundo Monetário Internacional e à receita do

\footnotetext{
${ }^{13}$ A social democracia assenta nas seguintes premissas: se as sociedades capitalistas querem singrar na competição com os modelos socialistas da sociedade que seduzem as classes populares, precisam de estar preparadas para reduzir a desigualdade social ao ponto de todos os cidadãos participarem na manutenção do atual estado de coisas. Isto é possível apenas através de elevados níveis de tributação; pelo envolvimento do Estado na produção de bens públicos tais como a educação, a saúde e os transportes; pela regulação das atividades capitalistas, a fim de proteger os trabalhadores e o meio ambiente; por algum tipo de indexação da produtividade "ganhos por ganhos" à segurança social. Tanto os discursos dos líderes europeus como os relatórios elaborados da burocracia de Bruxelas apontam a conclusão unânime: a social-democracia desapareceu de vez e não existe alternativa ao neoliberalismo e à austeridade.
} 
Banco Central Europeu que a Europa vê como tabu. É como se o mundo tivesse encontrado uma Europa que se perdeu de si. Conseguiremos ainda reconhecê-la como nossa?

É possível que a Europa se reencontre a partir de fora. Os protestos do Sul da Europa, detonadores de novas emergências políticas de esquerda, tinham bem presentes as lições da América Latina, sobretudo a nova relação partido-movimento, a nova articulação entre democracia representativa e democracia participativa, a reforma constitucional e, no caso da Espanha, a questão da plurinacionalidade. O modo como essas aprendizagens se vão plasmar no novo ciclo político que está a emergir na Europa do Sul é, por agora, uma incógnita. Mas, desde já, é possível especular o seguinte: se é verdade que as esquerdas europeias aprenderam com as muitas inovações das esquerdas latino-americanas, não é menos verdade que estas se "esqueceram" das suas próprias inovações e que, de uma ou de outra forma, caíram nas armadilhas da velha política onde as forças de direita facilmente mostram a sua superioridade dada a longa experiência histórica acumulada. Se as linhas de comunicação se mantêm nos dias de hoje, e sempre salvaguardando a diferença dos contextos, talvez seja tempo de as esquerdas latino-americanas aprenderem com as inovações que estão a emergir entre as esquerdas da Europa do Sul.

Democratizar a democracia é buscar uma "democracia de alta intensidade", combinado formas de democracia participativa e deliberativa com a democracia representativa. Esta conjugação pode fornecer instrumentos importantes para novas configurações de governação democrática, cidadania, representação e participação. Os novos modelos de participação e deliberação conduzirão, mais cedo ou mais tarde, a formas novas e mais exigentes de representação e de prestação de contas. O reconhecimento da riqueza da diversidade de experiências democráticas em diferentes partes do mundo - que denomino demodiversidade (Santos, 
2006) - pode ser um passo chave em direção à tão necessária renovação e reinvenção da democracia em contextos de aumento de diversidade cultural, étnica e religiosa, como é o caso da Europa. Esse reconhecimento apontará caminhos possíveis para a resolução de tensões, ou mesmo divergências, entre formas de deliberação e de consulta popular locais e temáticas, que vêm proliferando na Europa, e a construção de políticas através da democracia representativa ou por delegação aos níveis nacional e da União Europeia.

\subsection{Constitucionalismo transformador}

O constitucionalismo moderno tem como pressupostos as ideias de unidade, uniformidade e homogeneidade: um Estado soberano, uma nação, uma lei, uma burocracia e estrutura institucional, uma cultura, uma identidade, um sistema de educação, etc. Nas últimas três décadas, dois processos políticos diferentes questionaram seriamente o constitucionalismo moderno. Por um lado, em África e na América Latina (mas também no Canadá e na Nova Zelândia e em menor grau na Austrália) temos vindo a assistir à emergência de novos atores sociais coletivos - na maioria dos casos povos indígenas ou maiorias nacionais anteriormente oprimidas, como na África do Sul - com força para colocar na agenda política uma transformação radical do status quo constitucional, reivindicando nada menos do que a refundação do Estado numa base multicultural e intercultural (Santos, 2010). Estas reivindicações vêm sendo sustentadas pelas ideias de justiça histórica e reparação face à opressão colonial e pós-colonial. O sucesso destas lutas em países como a África do Sul, a Índia, o Brasil, a Bolívia ou o Equador deu origem a um constitucionalismo pós-colonial, que ergueu as bandeiras da interculturalidade, do pluralismo jurídico, da demodiversidade, da plurinacionalidade e da participação cidadã, e alimentou um otimismo assente na ideia de constitucionalismo intercultural e plurinacional. 
Por outro lado, o labirinto constitucional da União Europeia, ainda que marcadamente distinto do processo político acima referido, questiona também o princípio de unidade e de exclusividade do Estado soberano, reivindica novas soluções institucionais internamente diversas e, sobretudo, levanta a questão da legitimidade para a criação uma nova constituição. Ambos os percursos parecem apontar para um processo irreversível de refundação do Estado moderno. Nos dois casos, a novidade da situação é que a inércia das soluções constitucionais do passado conduziu a alguns ajustes transitórios, os quais denomino por constitucionalismo experimental.

No contexto da Europa, as questões constitucionais vão perdurar, sendo perpetuadas por novos alargamentos da União Europeia. No Sul global, o entendimento monocultural do Estado-Nação nunca correspondeu à realidade política. Mundo afora, uma vasta experiência de novas conceções de poder constitucional apontam para a refundação do Estado. Este é um terreno privilegiado para a aprendizagem mútua, para a inovação institucional e, sobretudo, para novas práticas de cidadania no futuro. Por outras palavras, toda a experiência além-Europa pode ser convocada para contribuir para uma melhor compreensão do processo constitucional na Europa e eventualmente para propor novas soluções institucionais.

Até que ponto estamos abertos e preparados para viver num mundo de possibilidades partilhadas, de modos de produção de sentido transformador, de modos desafiantes de expressão, de maneiras contestatárias de conceber o mundo? Tal como diversos autores propuseram - ao descreverem o novo constitucionalismo como 'pós-nacional', 'transnacional' ou 'pluridimensional' - o desafio que abrange a complexidade e a diversidade reside na produção de um novo pensamento constitucional que convoque não só a própria essência de Estado, mas que o leve além do Estado como modo de reclamar a sua legitimidade (Santos; Exeni, 2012; Santos; Grijalva, 2012). Em jogo, está a refundação do Estado moderno num contexto em que as instituições de Estado supranacional são ainda embrionárias. 
Vários anos volvidos após as reformas constitucionais da Bolívia e do Equador, os casos mais exemplares destes processos, fica claro o incumprimento de algumas das promessas que resultaram dessas vitórias. O que torna estes processos particularmente interessantes constitui talvez o seu maior desafio: como descolonizar um instrumento essencial da modernidade colonial, sem pôr em causa a sua centralidade? Este cenário é propício ao surgimento de contradições e choques, quase sempre resolvidos a favor da matriz eurocêntrica, que envolvem a dificuldade de traduzir conceitos não hegemónicos na linguagem jurídica moderna, a incompatibilidade entre as novas constituições e os compromissos nacionais assentes numa matriz jurídica internacional colonial e capitalista ou as tensões entre a nação cívica e as nações étnico-culturais.

Estas questões são tanto mais críticas na medida em que a processos constituintes extremamente ricos tendem a suceder-se poderes constituídos protagonizados por elites políticas que recusam romper com as hierarquias da modernidade. A discussão sobre a mestiçagem em causa ser colonialista ou descolonizadora é legítima e pertinente, mas a questão fundamental está, pois, no poder constituinte nascido nas ruas, nas lutas que levam ao rompimento da linha abissal e colocam os excluídos no seio do processo constitucional, que, de alguma forma, passa a representar os anseios e as expectativas de uma maioria invisibilizada nas Constituições anteriores. Um novo constitucionalismo experimental está a emergir, centrando-se nas noções de multinacionalidade, de interculturalidade e de soluções institucionais de diversidade interna. Estes processos políticos desafiam algumas das mais enraizadas tradições institucionais modernas, bem como os interesses sociais e políticos cristalizados; será, portanto de esperar que estes processos sejam prenhes de contradições e reveses, ainda que a sua direção histórica pareça irreversível. 
Sociologias, Porto Alegre, ano 18,no 43, set/dez 2016, p. 24-56

\section{Conclusão}

Por toda a história europeia, abundam conflitos, guerras, rivalidades, competições entre nações, que só foram resolvidas ou ultrapassadas após muito sofrimento. Só na Segunda Guerra Mundial, morreram entre 60 a 80 milhões de pessoas; foi o conflito militar mais mortal na história humana. Não obstante, foram raras as tentativas de sarar as feridas do passado por outros meios que não fossem por arranjos que deixaram ressentimentos latentes, sentimentos feridos, emoções dolorosas intocadas. Nunca se fez um esforço sustentado de reparação ou de reconciliação não-económica. De facto, a interpolítica europeia foi privilegiada em detrimento da intersubjetividade europeia.

Do mesmo modo, urge um confronto com o legado da história colonial europeia. Se, como tenho defendido, a modernidade ocidental é um paradigma fundado na tensão entre regulação e emancipação (Santos, 2000), haverá que reconhecer que esta dicotomia se aplica fundamentalmente às sociedades metropolitanas. Porém, nas sociedades coloniais predominou a dicotomia apropriação/violência, expressão do conflito entre os colonizadores e colonizados. No entanto, a força atuante desta tensão pôde permanecer invisibilizada para os contextos europeus, exatamente por ter lugar do outro lado da linha, num espaço invisível, feito inexistente e, por isso, incapaz de comprometer as alegações ocidentais sobre a universalidade da dicotomia regulação/emancipação. A zona colonial emerge como o território social da modernidade sumamente criado e mantido por uma ordem violenta, mas, ao mesmo tempo, suficientemente demarcado pelas linhas abissais para que a violência estrutural fosse estruturalmente invisível no Norte. Nesta invisibilização histórica da violência colonial, encontramos uma das expressões de como o colonialismo como relação social e epistemológica sobreviveu ao colonialismo como relação política. Contra o pensamento abissal que se articulou com 
colonialismo e a ciência moderna, só uma efetiva descolonização das relações políticas e dos saberes poderá permitir que a Europa seja parte num mundo transformado por aprendizagens globais.

Estou convicto de que, ou a Europa se compromete com um vasto processo de desaprendizagem/aprendizagem com o Sul global, ou estará condenada a cair nas mesmas divergências e disputas internas, altamente problemáticas, que num passado recente resultaram em consequências trágicas. Trata-se de um empreendimento difícil, dada a inclinação secular da Europa para olhar o mundo de fora como objeto de dominação, em vez que o encarar como parceiro de uma cooperação mútua enriquecedora. Sendo difícil, não é de todo impossível, se as condições que aqui apresento forem tomadas em consideração. As aprendizagens mútuas são essenciais para uma reinvenção da Europa capaz de aprender com o Sul. Estas aprendizagens são traduções interculturais fortemente informadas pelos sofrimentos, ressentimentos e linhas abissais forjados no longo tempo do colonialismo, pela insustentabilidade de um triunfalismo civilizacional e, finalmente, pela recusa do fatalismo de um mundo sem diversidade e sem alternativas de futuro. Neste mergulho ao encontro das "epistemologias do sul," talvez esteja a chave para a única nova visão da Europa pela qual vale a pena lutar.

Boaventura de Sousa Santos é Doutor em Sociologia do Direito pela Universidade de Yale (1973), Professor Catedrático Jubilado da Faculdade de Economia da Universidade de Coimbra e Distinguished Legal Scholar da Universidade de Wisconsin-Madison. Foi também Global Legal Scholar da Universidade de Warwick e Professor Visitante do Birkbeck College da Universidade de Londres. É Director do Centro de Estudos Sociais da Universidade de Coimbra e Coordenador Científico do Observatório Permanente da Justiça Portuguesa.. $\$ bsantos@ces.uc.pt 


\section{Referências}

1. AN-NA'IM, A. A. (org.), Human Rights in Cross-Cultural Perspectives. A Quest for Consensus. Filadélfia: University of Pennsylvania Press, 1992.

2. AN-NA'IM, A. A. Toward an Islamic Reformation. Siracusa: Syracuse University Press, 1990

3. DAHRENDORF, R. et al. Whose Europe? Competing Visions for 1992. Londres: Institute of Economic Affairs, 1989.

4. DUSSEL, E. Hacia una filosofía política crítica. Bilbao: Desclee de Brouwer, 2001.

5. FALK, R. Achieving Human Rights. New York: Routledge, 2009.

6. HABERMAS, J. The Crisis of the European Union. Cambridge: Polity, 2012.

7. HABERMAS, J. Europe: The Faltering Project. Cronin, Ciaran. Trans. Malden, MA: Polity Press, 2009.

8. HOBSBAWM, E. On History. Nova lorque: New Press, 1997.

9. KUNDERA, M. The tragedy of central Europe. The New York Review of Books, 31,1984

10. LAS CASAS, B. (1992), Obras Completas, Tomo X. Madrid: Alianza Editorial, 1992.

11. MIGNOLO, W. Local Histories/Global Designs. Princeton: Princeton University Press, 2000.

12. MOYN, S. The last utopia: human rights in history. Cambridge, Mass.: Belknap Press of Harvard University Press, 2010.

13. NEEDHAM, J. Science and Civilization in China, 6 Volumes. Cambridge: Cambridge University Press, 1954.

14. ORBE, R. Manual para Defensores y Defensoras de Derechos Humanos y de la Naturaleza. Quito: Fundación Regional de Asesoría en Derechos Humanos, INREDH, 2010.

15. QUIJANO, A. Colonialidad del poder y clasificación social. Journal of WorldSystems Research, v. 6, n. 2 p. 342-386, 2000.

16. SAID, E. Orientalism. Nova lorque: Vintage Books, 1979.

17. SANTOS, B. de S. Epistemologies of the South. Justice against Epistemicide. Boulder/Londres: Paradigm Publishers, 2014. 
18. SANTOS, B. de S. Se Deus fosse um ativista dos direitos humanos. São Paulo: Cortez Editora, 2013.

19. SANTOS, B. de S. Ensaio contra a autoflagelação. Coimbra: Almedina, 2011.

20. SANTOS, B. de S. Refundación del Estado en América Latina. Perspectivas desde una epistemología del Sur. Bogotá: Siglo del Hombre Editores, 2010.

21. SANTOS, B. de S. Para além do Pensamento Abissal: Das linhas globais a uma ecologia de saberes, Revista Crítica de Ciências Sociais, v. 78, p. 3-46, 2007.

22. SANTOS, B. de S. A gramática do tempo. Para uma nova cultura política. São Paulo: Editora Cortez, 2006.

23. SANTOS, B. de S. (Org.). Democratizar a democracia: os caminhos da democracia participativa. Rio de Janeiro: Civilização Brasileira, 2002a.

24. SANTOS, B. de S. Democracia e Participação: o Caso do Orçamento Participativo de Porto Alegre. Porto: Afrontamento, 2002b.

25. SANTOS, B. de S. A Crítica da Razão Indolente. Contra o desperdício da experiência. Porto: Edições Afrontamento, 2000.

26. SANTOS, B. de S.; AVRITZER, L. Introdução: Para ampliar o cânone democrático. In: SANTOS, B. de S. (Org.). Democratizar a democracia: os caminhos da democracia participativa. Rio de Janeiro: Civilização Brasileira, 2002.

27. SANTOS, B. de S.; EXENI, J. L. (Org.). Justicia Indígena, Plurinacionalidad e Interculturalidad en Bolivia. Quito: Ediciones Abya Yala y Fundación Rosa Luxemburg, 2012.

28. SANTOS, B. de S.; GRIJALVA, A. (Org.). Justicia Indígena, Plurinacionalidad e Interculturalidad en Ecuador. Quito: Ediciones Abya Yala y Fundación Rosa Luxemburg, 2012.

29. SEPÚLVEDA, J. G. de. Tratado sobre las Justas Causas de la Guerra contra los Índios. México: Fondo de Cultura Economica, 1979.

30. SETON-WATSON, H. Thoughts on the Concept of West and East in Europe. Government and Opposition, 20: 156-165, 1985.

31. SHORE, C. Inventing the 'People's Europe': Critical Approaches to European Community. Cultural Policy, 28(4), 779-800, 1993.

32. TAYLOR, C. A Secular Age. Cambridge, MA: Harvard University Press, 2007.

33. WALLACE, W. The Transformation of Western Europe. Londres: Pinter, 1990. 
Sociologias, Porto Alegre, ano 18,no 43, set/dez 2016, p. 24-56

34. WALLERSTEIN, Immanuel. The Modern World-System. New York: Academic Press. 1979.

35. WEBER, M. A Ética Protestante e o espírito do Capitalismo. Lisboa: Presença, 1990.

36. YOUNG, R. Postcolonialism: an Historical Introduction. Oxford: Blackwell Publishers, 2001.

Recebido: 28.06.2016

Aceite final: 20.07.2016 